\title{
DETERMINATION OF MAXILLARY ANTERIOR TEETH WIDTH USING INNER CANTHAL DISTANCE WITH RESPECT TO AGE GENDER AND ETHINICITY
}

\author{
Naseer Ahmed, Maria Shakoor Abbasi, Danish Azeem Khan*, Shiza Khalid, Warda Jawed, Momina Mahmood \\ Altamash Institute of Dental Medicine, Karachi Pakistan, *Combined Military Hospital Khuzdar/National University of Medical Sciences \\ (NUMS) Pakistan
}

\begin{abstract}
Objective: To evaluate the relationship between inner canthal distance and maxillary anterior teeth width with respect to age, gender and ethnicity.

Study Design: Cross sectional study.

Place and Duration of Study: Altamash Institute of Dental Medicine, Karachi, from Aug 2019 to Jan 2020.

Methodology: One hundred participants from both genders with full permanent dentition, no interdental space or pathology and facial symmetry were included in this study. The measurements were carried out with digital Vernier caliper. SPSS-25 was used for statistical analysis.

Results: The mean \pm SD of inner canthal distance and width of maxillary anterior teeth were $2.99 \mathrm{~cm} \pm 0.46$ and $3.82 \mathrm{~cm} \pm 0.35$ respectively. A significant difference was found between gender $(p=0.037)$ and inner canthal distance. The maxillary anterior teeth width and inner canthal distance varies amongst different ethnicities $(p=0.01)$. The inner canthal distance does not vary with advancing age $(p=0.87)$ whereas width of maxillary anterior teeth varies $(p=0.04)$. A weak correlation value of 0.47 was found between inner canthal distance and maxillary anterior teeth width.

Conclusion: This research suggests that there is a weak relationship between inner canthal distance and maxillary anterior teeth width. Therefore, a multiplication ratio of 1.27 is advised to get combined mesiodistal width of maxillary anterior teeth. Additionally, the value of both differs in various local ethnicities. Inner canthal distance does not vary with age though has significant gender disparities while maxillary anterior teeth width remains constant.
\end{abstract}

Keywords: Ethnicity, Inner canthal distance, Maxillary anterior teeth width.

This is an Open Access article distributed under the terms of the Creative Commons Attribution License (http://creativecommons.org/licenses/by/4.0), which permits unrestricted use, distribution, and reproduction in any medium, provided the original work is properly cited.

\section{INTRODUCTION}

It is common knowledge that a person's smile is one of the determining factors in the evaluation of their facial charm in the eyes of the beholder ${ }^{1}$. A beautiful dentofacial profile is also linked to good self-esteem and confidence ${ }^{1}$. Hence, loss of teeth not only affects the facial appearance but can also create psychological implications for an individual. It is therefore imperative that suitable replacements are made available, which are both aesthetically pleasant and functionally comfortable ${ }^{1}$.

Mc Arthur suggests that patients' natural teeth are the optimal guides for replacement and their records should be used wherever con-

Correspondence: Dr Danish Azeem Khan, Dental Unit, Combined Military Hospital, Khuzdar Pakistan

Received: 19 May 2020; revised received: 18 Jun 2020; accepted: 20 Jul 2020 ceivable. Pre-extraction records including casts, radiographs, facial photographs and previous records are the most reliable guiding mediums for replacement. However, these records might not be available sometimes, and many methods have been developed as compensation ${ }^{2}$.

The early approaches of choosing tooth size were based on "trial and error" till both the patient as well as the dental practitioner gets satisfied $^{3}$. Frush and Fisher introduced their popular "Dentogenic theory" in 19584, which used the SPA factor (Sex, personality and age) to select teeth. Although these factors are still taken into consideration, but practitioners now prefer more systematic and scientific methods of tooth selection ${ }^{1}$.

According to Lombardi, "the mould selected should have a pleasing proportion with facial 
anatomy and thereby harmonize with factors necessary to unify if with realism" 5 . Consequently, many facial anatomical structures have been analysed, including Bizygomatic width (BZW), interpupillary distance (IPD), Interalar width (IAW), Inner canthal distance (ICD) and Intercommisural width (ICMW) ${ }^{5-7}$.

ICD is the measurement of the distance between the two medial canthi of the eyes ${ }^{8}$. Wazzan et $a l^{6}$, investigated the association between ICD and four maxillary anterior teeth and found a weak relationship between them. On the other hand, Abdullah et al , studied the relationship between six maxillary anterior teeth and ICD and concluded that the multiplication factor of 1.35 can be used as a reliable estimator. Gomes et $a l^{10}$, and Tripathi et al11, have also found a correlation between ICD and the tips of maxillary canines.

Pakistan has a vast ethnic diversity. It is well known that members of different ethnic groups have different facial forms and features. This in turn can affect tooth form and size in different individuals. A study sample of a particular group would not do justice to the population of Pakistan which is why this article aims to correlate the relationship between ICD and maxillary anterior teeth width (MATW) with age, gender and various ethnicities. This study will help clinicians to select appropriate size of teeth for edentulous and partially edentulous patients utilizing inner canthal distance measurement in the absence of pre extraction record.

\section{METHODOLOGY}

A cross-sectional study was carried out at Altamash Institute of Dental Medicine to obtain the relationship between the ICD and MATW and see the variation they have in different ages, gender and ethnicities in Pakistan. The duration of this study was 6 months from August' 2019 to January' 2020. Openepi calculator was used to calculate the sample size of this study. Considering the mean value of innercanthal distance $31.69 \pm 3.6$. Keeping 95\% confidence interval and
$80 \%$ power of test. The total sample size calculated was 100.

The study was approved by ethical and review committee; AIDM/EC/06/2019/11. Non probability convenience sampling technique was used to select participants. Additionally, as a protocol an informed consent was sought out prior form participants at interview stage. The patients were examined in the general outpatient department. Using this information, theywere selected for the study according to our exclusion and inclusion criteria. Both male or female patients in the age range of 16-40 years, having only permanent dentition, good oral hygiene with all anterior teeth present, no interdental space or any other pathology or therapy which could alter tooth to tooth relation were included in this study. Those having class-1 dentoskeletal relationship and no facial asymmetry were also included. The patients with existing periodontal diseases or having an anterior tooth chipped off or fractured were not included.

The participants were seated in a dental chair with an upright posture and head supported so that they could look forward still at the horizon with the base of the mouth parallel to the floor. Cheek retractors were used to retract the cheeks from both sides to prevent error and display full set of anterior teeth. The ICD was measured using a digital Vernier calliper and avalue was recorded. The mesiodistal width of six maxillary anterior teeth was recorded from tip to tip of canine teeth collectively. The method was adopted from Abdullah et al ${ }^{9}$. Each measurement was recorded thrice, and the mean value was entered in the patient form for validity of measurement. For operator reliability $20 \%$ participants were remeasured after two weeks by an independent investigator maintaining the same settings. The data obtained were subjected to correlation tests by Dahlberg formula ${ }^{25}$ the measurement had a strong test retest reliability of 0.78 .

The IBM SPSS statistics for windows, version 25.0 (Armonk, NY: IBM Corp) was used for statistical analysis. Descriptive statistics were carried 
out for qualitative and quantitative variables. Pearson correlation test was applied for any association between ICD and MATW. Paired t-test was used to analyse the effect of ICD, MATW with age and Independent $t$-test for gender. Oneway ANOVA test was applied to detect variation of ICD and MATW in different ethnicities. A $p$-value of $\leq 0.05$ was considered statistically significant.

\section{RESULTS}

A total of 100 subjects participated in this study. The mean age was $26.6 \pm 5.93$ years. Females $53(53 \%)$ and males 47 (47\%). All the participants belonged to different ethnicities of Pakistan. Forty one were Sindhi, 19 were Punjabi, 24 were Pashtuns and 14 were Balochis. The data collected and analysed for all ethnic group is des- tuns than other ethnic groups.The second highest reading for ICD was found in the Balochi's with $3.02 \pm 0.26 \mathrm{~cm}$ for ICD and $3.77 \pm 0.33 \mathrm{~cm}$ for MATW. The values of ICD and MATW for Sindhi's were $2.97 \pm 0.42 \mathrm{~cm}$ and $3.80 \pm 0.34 \mathrm{~cm}$ respectively. In Punjabi's, the mean ICD was 2.94 $\pm 0.59 \mathrm{~cm}$ and MATW was $3.86 \pm 0.35 \mathrm{~cm}$. In this study a significant difference $(p=0.01)$ between ethnicities in both ICD and MATW values was found. Table-II depicted that the distance between the ICD and MATW appears to be slightly greater in males than females with the mean ICD value $3.08 \pm 0.43 \mathrm{~cm}$ for males and $2.89 \pm 0.48 \mathrm{~cm}$ for females while the mean value for MATW was $3.88 \pm 0.38 \mathrm{~cm}$ and $3.76 \pm 0.32 \mathrm{~cm}$ respectively. A significant variation between gender and ICD $(p=0.037)$, and no significant difference between

Table-I: Characteristics of inner canthal distance and maxillary anterior teeth width in different ethnicity $\mathrm{n}=100$.

\begin{tabular}{|c|c|c|c|c|c|}
\hline \multicolumn{2}{|c|}{ Ethnicity } & $\begin{array}{c}\text { Inner Canthal Distance } \\
(\mathrm{cm})\end{array}$ & $p$-value & $\begin{array}{c}\text { Maxillary Anterior } \\
\text { Teeth Width }(\mathrm{cm})\end{array}$ & $p$-value \\
\hline \multirow{2}{*}{ Sindhi } & Mean \pm SD & $2.97 \pm 0.42$ & \multirow{10}{*}{0.01} & $3.80 \pm 0.34$ & \multirow{10}{*}{0.01} \\
\hline & $\mathrm{n}$ & 41 & & 41 & \\
\hline \multirow{2}{*}{ Balochi } & Mean $\pm S D$ & $3.02 \pm 0.26$ & & $3.77 \pm 0.33$ & \\
\hline & $\mathrm{n}$ & 14 & & 14 & \\
\hline \multirow{2}{*}{ Pashtun } & Mean \pm SD & $3.11 \pm 0.48$ & & $3.82 \pm 0.41$ & \\
\hline & $\mathrm{n}$ & 24 & & 24 & \\
\hline \multirow{2}{*}{ Punjabi } & Mean \pm SD & $2.94 \pm 0.59$ & & $3.86 \pm 0.35$ & \\
\hline & $\mathrm{n}$ & 19 & & 19 & \\
\hline \multirow{2}{*}{ Others } & Mean \pm SD & $2.30 \pm 0.00$ & & $4.20 \pm 0.00$ & \\
\hline & $\mathrm{n}$ & 2 & & 2 & \\
\hline
\end{tabular}

Table-II: Effect of gender withinner canthaldistance and maxillary anterior teeth width $\mathbf{n}=100$.

\begin{tabular}{|c|c|c|c|c|c|}
\hline & ler & $\begin{array}{l}\text { Inner Canthal } \\
\text { Distance (cm) }\end{array}$ & $p$-value & $\begin{array}{l}\text { Maxillary Anterior } \\
\text { Teeth Width }(\mathrm{cm})\end{array}$ & $p$-value \\
\hline Male & Mean \pm SD & $3.08 \pm 0.43$ & \multirow{3}{*}{0.03} & $3.88 \pm 0.38$ & \multirow{3}{*}{0.87} \\
\hline Female & Mean \pm SD & $2.89 \pm 0.48$ & & $3.76 \pm 0.32$ & \\
\hline Total & Mean \pm SD & $2.99 \pm 0.46$ & & $3.82 \pm 0.35$ & \\
\hline
\end{tabular}

Table-III: Effect of age on inner canthal distance and maxillary anterior teeth width $\mathbf{n}=\mathbf{1 0 0}$.

\begin{tabular}{c|c|c|c|c|c}
\hline & Age & Inner Canthal Distance & $\boldsymbol{p}$-value & Inner Canthal Distance & $\boldsymbol{p}$-value \\
\hline Mean \pm SD & $26.6 \pm 5.93$ & $2.99 \pm 0.46$ & 0.87 & $3.82 \pm 0.35$ & 0.04 \\
\hline
\end{tabular}

Table-IV: Correlation between inner canthal distance and maxillary anterior teeth width $n=100$.

\begin{tabular}{c|c|c}
\hline & Mean \pm SD $(\mathbf{c m})$ & Pearson Correlation \\
\hline Maxillary Anterior Teeth Width & $2.99 \pm 0.46$ & 0.47 \\
\hline Inner Canthal Distance & $3.82 \pm 0.35$ & \multirow{2}{*}{0.077 Was } \\
\hline
\end{tabular}

cribed in table-I. The distance between the innercanthal $3.11 \pm 0.48 \mathrm{~cm}$ and maxillary anterior teeth width $3.82 \pm 0.41 \mathrm{~cm}$ was highest in Pash- gender and MATW $(p=0.87)$ was found. Additionally, a significant difference was found between MATWand advancing age $(p=0.04)$ though ICD 
with advancing age was statistical insignificant $(p=0.87)$ as depicted in table-III. There was no relationship between ICD and MATW in participants (rp 0.47) as presented in table-IV. A multiplication ratio of 1.27 was found between the ICD and MATW. To obtain the multiplication ratio, the mean width of MATW $3.82 \mathrm{~cm}$ was divided by ICD width $2.99 \mathrm{~cm}$.

\section{DISCUSSION}

When planning a prosthetic treatment for a patient, it is important to keep an organizational balance with the rest of the dentofacial structures, in a way that can fulfil the aesthetic harmony of the face while also optimizing the functional efficiency of the prosthesis ${ }^{12}$. In the absence of preextraction records, methods utilizing facial landmarks have been developed to reliably predict the size and shape of the prosthesis,13-15. In this study we used the ICD to determine the MATW. The interest in this landmark is due to different reasons; including, the relative dimensional stability of this landmark as regards to age ${ }^{16,17}$, also being an easy point to recognize and measure with basic instruments ${ }^{18}$.

According to Laestadius et al16, 78\% of the adult inner canthal distance is achieved by 1 year of age, and subsequently the growth rate markedly decreases as compared to that of the outer orbital dimension making ICD a stable anthropometric parameter. This was reflected in our study as the relationship between age and ICD was found to be non-significant, ( $p$-value $=0.87$ ). With regards to MATW, our study showed significant relationship of the parameter with age $(p$-value $=0.004)$, which shows the teeth width changes with advancing age ${ }^{7}$.

Additionally in our study the mean value of ICD was $(29.9 \mathrm{~mm} \pm 0.47)$ which is lower than that of Friehofer et al17, (31.2 $\mathrm{mm} \pm 2.5)$, Wazzan et $a l^{6},(31.92 \mathrm{~mm} \pm 2.80)$, Agribede et al ${ }^{19},(31.7 \mathrm{~mm} \pm$ $0.376)$ but similar to that of Laestadius et al16, $(30 \mathrm{~mm} \pm 0.5)$ and greater than Deogade et $a l^{20}$, $(26.22 \mathrm{~mm} \pm 3.81)$. The range level of ICD was 27$38 \mathrm{~mm}$, likein Friehofer et al17, study $(28-35 \mathrm{~mm})$ while the findings of Agribede et al19, (20-43 mm) contradicts.

The mean MATW in our study was $(38.2 \mathrm{~mm}$ \pm 0.36 ) with a rangelevel of $28-46 \mathrm{~mm}$. This was similar to Baleegh et al $21,(38.37 \pm 2.81)$, but significantly smaller than that of Wazzan et al6, (45.23 $\mathrm{mm} \pm 2.74)$, Agribede et al ${ }^{19},(47.4 \mathrm{~mm} \pm 0.951)$, Scandrett et $a l^{7},(53.61 \mathrm{~mm})$ and Deogade et al20, $(43.86 \mathrm{~mm} \pm 3.33)$.

Moreover, in our study there was weak association (0.47) between ICD and MATW with a significance difference of $(p=0.001)$. The ICD as an anthropometric tooth size guide cannot be used reliably without addition and subtraction to predict the MATW in edentulous patients ${ }^{10}$. To strengthen the evidence Mishra et $a l^{2}$, and Deogade et $a l^{20}$, also found an even weaker significant correlation between MATW and ICD $(\mathrm{rp}=0.218)$ and $0.038(p<0.05)$ respectively, and they stated that it cannot be used as a tentative predictor for planning of prosthesis. However, Wazzan et al compared the relationship of ICD with both MATW and the width of central incisors and concluded that the relationship with MATWwas relatively higher and more reliable $(\mathrm{rp}=0.303)$ than that of 2 central incisors $(\mathrm{rp}=0.209)$.

In our study, the multiplication ratio between ICD and MATW was found to be 1.27 which corresponds to the factor of 1.35 found by Abdullah et al ${ }^{9}$, but in contrast to Arun et al12, 1.61 and 1.4266 by Wazzan et $a l^{6}$. These differences have been attributed not only to the difference in ethnicities of the participants in each study $2,6,20$, but also the methods used to measure the MATW.

The cephalometric norms differ based on ethnicities ${ }^{22}$. Likewise, Mishra et $a l^{2}$, found a significant difference in facial features amongst Mongoloid and Aryan raceswhile Lucas et al10, in the Brazilian population noted larger ICD in men of "marked Asiatic features"10.

Since Pakistan has such a diverse racial background, this study aimed to investigate the relationship between local ethnicities and ICD in order to see if there was a significant difference 
that could affect the dental practice in Pakistan. The results of our study showed that the distance between the inner canthi of the eyes is the greatest in the Pashtun population $(31.1 \mathrm{~mm})$. A significant relationship was noted between ethnicity and ICD $(p=0.01)$. Likewise, the greatest mean MATW was also found in the Pashtun population (38.2mm), and the $p$-value was also significant (0.01), which means that both these parameters were affected by ethnicity in our study ${ }^{24}$.

The research by Friehofer ${ }^{17}$, and Garib et al 23 , have noted that there was no significant difference of gender with ICD. In our study mean ICD value was higher in males $(30.8 \mathrm{~mm})$ as compared to females $(28.9 \mathrm{~mm})$ with a significant difference $p=0.037$. This finding was in accordance with Ahmed et $a l^{3}$, and Abdullah et al ${ }^{18}$. The mean MATW was only slightly higher in males (38.8 $\mathrm{mm})$ as compared to females $(37.6 \mathrm{~mm})$, withno significant difference $p=0.87$. This was in accordance to the investigations of Arun et al12.

The ICD being an anthropometric reference point is crucial in determining the anterior teeth width during restoration of aesthetics, however variations could exist on individual, racial and ethnic basis. Valid metrics are necessary to implement ICD as a teeth selection guideline, therefore in our study in spite of no relation with anterior teeth width a multiplication ratio was proposed for future use and incorporation in patient management.

\section{LIMITATIONS OF STUDY}

Limitations of using a Vernier calliper as a measuring device, as some subjects had difficulty to easily allow placement of the beaks of the calliper in the medial canthus of eye. Also, ICD is a soft-tissue landmark and due to inconsistent pressure, variations in readings were observed in the some patients. We overcame the chances of operator bias and enhances consistency of measurement by taking the mean of multiple readings. Despite the limitations, our study provide valuable information on relation between ICD and MATW.

\section{CONCLUSION}

This research suggests that there is a weak relationship between inner canthal distance and combined anterior teeth width. Therefore, to select the size of maxillary anterior teeth ICD must be multiplied by factor of 1.27 to get MATW. Additionally, the ICD and MATW differs in various local ethnicities. As far as advancing age is concerned, the ICD does not vary though MATW varies. Lastly, the ICD has significant gender disparities while MATW remains constant.

\section{ACKNOWLEDGEMENT}

The authors are grateful to Research Ethics and Review Committee of Altamash Institute of Dental Medicine, Pakistan and Dental Unit, Combined Military Hospital, Khuzdar for facilitation and support in this study. Also, to Dr. Asma Rizwan and Dr.Yusra Kanwal for help in validation of research.

\section{CONFLICT OF INTEREST}

This study has no conflict of interest to be declared by any author.

\section{REFERENCES}

1. Rawat A, Godbole SR, Sathe S, Patidar N, Ramteke S. Evaluation of relation between bizygomatic width and mesiodistal dimension of maxillary central incisor in indian population: An In Vivo Study. Int J Sci Stud 2015; 3(6): 38-42.

2. Mishra MK, Singh RK, Parajuli PK, Shrestha P, Baral D. A comparative study to find out the relationship between the inner inter-canthal distance, interpupillary distance, inter-commissural width, inter-alar width, and the width of maxillary anterior teeth in Aryans and Mongoloids. Clinical Cosmetic Investigational Dentis 2016; 8(1): 29-34.

3. Ahmed N, Abbas M, Naz A, Maqsood A. Correlation between innercanthal distance and the mesiodistal width of the maxillary central incisors. Isra Med J 2015; 7(3): 139-40.

4. Basavanna JM, Barua DR, Gaurav A. Smile designing in complete denture-an overview. J Pearldent 2016; 7(1): 1-8.

5. Lombardi RE. The principles of visual perception and their clinical application to denture esthetics. J Prosthet Dent 1973; 29(4): 358-82.

6. Al Wazzan KA. The relationship between intercanthal dimension and the widths of maxillary anterior teeth. J Prosthet Dent 2001; 86(6): 608-12.

7. Scandrett FR, Kerber PE, Umrigar ZR. A clinical evaluation of techniques to determine the combined width of the maxillary anterior teeth and the maxillary central incisor. J Prosthet Dent 1982; 48: (1): 15-22

8. Hayat N, Alkhairy S, Cheema A, Ehsan M. Normal interpupillary, inner canthal distance and outer canthal distance in 
a normal population of Pakistan. Pak J Med Sci 2019; 35(1): 50-55.

9. Abdullah MA, Stipho HD, Talic YF. The significance of inner canthal distance in prosthodontics. Saudi Dent J 1997; 9(1): 36-39.

10. Gomes VL, Gonçalves LC, do Prado CJ, Junior IL, de Lima Lucas B. Correlation between facial measurements and the mesiodistal width of the maxillary anterior teeth. J Esthet Restor Dent 2006; 18(4): 196-05.

11. Tripathi S, Singh RD, Chand P, Kumar L, Singh GK. A study to correlate various facial landmarks with intercanine distance. Ind J Dent Res 2018; 29(4): 440.

12. Arun Kumar KV, Gupta SH, Sandhu HS. Determination of mesiodistal width of maxillary anterior teeth using inner canthal distance. Med J Arm For Ind 2015; 71(Suppl 2): S376-81.

13. Gupta R, Luthra RP, Sharma A. A comparative evaluation of the inter-relationship between inner-canthal distance, inter-alar width and inter-Pupillary distance with respect to inter canine width amongst the population of Himachal Pradesh. J Adv Med Dent Sci Res 2016; 4(6): 186-92.

14. Mahmood Z. Correlation between Interalar Width and Size of Natural Maxillary Anterior Teeth. Biomedica 2019; 35(3): 1-4.

15. Rokaya D, Suttagul K, Sapkota B, Maharjan SK. Gender based comparison of the relationships of maxillary anterior teeth and facial measurements. J Inter Dent Med Res 2018; 11(2): 465-69.

16. Laestadius ND, Aase JM, Smith DW. Normal inner canthal and outer orbital dimensions. J Pediatr 1969; 74(3): 465-68.
17. Freihofer HP. Inner intercanthal and interorbital distances. J Maxillofac Surg 1980; 8(4): 324-26.

18. Abdullah MA. Inner canthal distance and geometric progression as a predictor of maxillary central incisor width. J Prosthet Dent 2002; 88(1): 16-20.

19. Arigbede AO. Size of maxillary anterior teeth in relation to selected facial anatomic landmarks among a group of subjects in port harcourt. J Advan Med Res 2016; 14(9): 1-6.

20. Deogade SC, Mantri SS, Sumathi K, Rajoriya S. The relationship between innercanthal dimension and interalar width to the intercanine width of maxillary anterior teeth in central Indian population. J Ind Prosth Soc 2015; 15(2): 91-97.

21. Baleegh S, Choudhry Z, Malik S, Baleegh H. The Relationship between widths of upper anterior teeth and facial widths. Pak Oral Dent J 2015; 35(4): 742-45.

22. Alkhodary MA. Virtual evaluation of Complete dentures smile anatomical relationships. Egyptian Dent J 2018; 64(2): 753-61.

23. Neda AK, Garib BT. Selecting maxillary anterior tooth width by measuring certain facial dimensions in the Kurdish population. J Prosthet Dent 2016; 115(3): 329-34.

24. Faruqui S, Malikahaider SY, Ahmed N. Esthetic and function evaluation after treatment with removable dentures by patients, lay persons, dentists in a dental school of Pakistan. Pak Oral \& Dent J 2015; 35(4): 730-34.

25. Dahlberg A. Statistical methods for medical and biological students. New York: Inter Sci Pub 1940; 2(4158): 358-59. 